\title{
FCER2 Negative
}

National Cancer Institute

\section{Source}

National Cancer Institute. FCER2 Negative. NCI Thesaurus. Code C131487.

Indicates that expression of FCER2 has not been detected in a sample. 